\title{
Isotope Effects of Water Adsorption at the Mineral Interface
}

\author{
JUSKE HORITA AND CHANGJIE LIU ${ }^{1}$ \\ ${ }^{1}$ Department of Geosciences, Texas Tech University, TX \\ 79409-1053 (juske.horita@ttu.edu)
}

Physical and chemical interactions of water at the surface of various solids/minerals is of impotance to a wide range of issues in geochemsitry, envirnmental sciences, an chemical engineering. Physical sorption (physisorption) of water molecules to the surface via van der Waals forces is the first step of these interactions. Extensive studies have been carried out on the structural and dynamic properties of water molecules adsorbed on the surface of natural minerals and engineered materials by means of both experiemntal and molecular simulation methods. However, the isotopic property of adsorbed water at the interface is still poorply characterized.

We have been conducting a series of systematic experimental studies on the isotope effects of water adsorption on engineered mesoporous ( 6 and $15 \mathrm{~nm}$ ) silica/alumina and various clay minerals as a function of the relative pressure of water $(p / p o)$ at $30^{\circ} \mathrm{C}$. It has been demonstrated that the equilibrium isotope fractionation factor

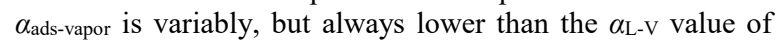
bulk liquid water and water vapor across the entire range of $p / p o$ values for both ${ }^{2} \mathrm{H} /{ }^{1} \mathrm{H}$ and ${ }^{18} \mathrm{O} /{ }^{16} \mathrm{O}$ isotopes $[1,2]$. From our data, we can constrain the isotope fractionation factor between the first monolayer of adsorbed water and water vapor: $\alpha_{\text {ads-vapor }} \sim 1.012-1.015\left({ }^{2} \mathrm{H} /{ }^{1} \mathrm{H}\right)$ and $\sim 1.000-1.004$ $\left({ }^{18} \mathrm{O} /{ }^{16} \mathrm{O}\right)$. These values suggest that the first monolayer of adsorbed water is more 'vapor-like' rather than 'liquid-like,' consistent with results from many spectroscopic studies. The triple oxygen isotope fractionation of adsorbed water, ${ }^{17} \theta$ $=\ln \alpha_{\text {ads-vapor }}\left({ }^{17} \mathrm{O} /{ }^{16} \mathrm{O}\right) / \ln \alpha_{\text {ads-vapor }}\left({ }^{18} \mathrm{O} /{ }^{16} \mathrm{O}\right)$, appears to be greater than that of the bulk liquid-vapor system.

The above, somewhat peculiar isotopic properties of the interfacial and confined water is combined results of the redshift of the OH-stretching vibrational frequency and the appearance of librational frequency upon adsorption. However, detailed property of adsorbed water over the entire frequency is not well characterised yet. The non-liquid behaviour of adsorbed water on many solids/minerals below the saturation challenges the long-held assumption in isotope hydrology that soil water behaves like bulk liquid water.

REFERENCE:

[1] Lin \& Horita (2016), GCA 184, 257-271; [2] Lin, Horita, $\&$ Abe (2018), GCA 223, 520-536 